\title{
Laboratory characterisation of Salmonella enterica serotype Typhi isolates from Zimbabwe, 2009-2017
}

Tapfumanei Mashe ${ }^{1,2,3^{*}}$ (D), Muchaneta Gudza-Mugabe², Andrew Tarupiwa², Ellen Munemo², Sekesai Mtapuri-Zinyowera ${ }^{2}$, Shannon L. Smouse ${ }^{5}$, Arvinda Sooka ${ }^{5}$, Babill Stray-Pedersen ${ }^{4}$, Anthony M. Smith ${ }^{5,6}$ and Joshua Mbanga'

\begin{abstract}
Background: Typhoid fever remains a major public health problem in Zimbabwe with recurrent outbreaks reported since 2009. To provide guidance on appropriate treatment choice in order to minimise the morbidity and mortality of typhoid fever and prevent large scale outbreaks, we investigated the antimicrobial susceptibility patterns, prevalence of Salmonella enterica serotype Typhi (S. Typhi) H58 haplotype and molecular subtypes of S. Typhi from outbreak strains isolated from 2009 to 2017 in Zimbabwe and compared these to isolates from neighbouring African countries.
\end{abstract}

Methods: Antimicrobial susceptibility testing was performed on all isolates using the disk diffusion, and E-Test, and results were interpreted using Clinical and Laboratory Standards Institute (CLSI) guidelines (2017). S. Typhi H58 haplotype screening was performed on 161 (58.3\%) isolates. Pulsed-field gel electrophoresis (PFGE) was performed on 91 selected isolates across timelines using antibiotic susceptibility results and geographical distribution (2009 to 2016).

Results: Between 2009 and 2017, 16,398 suspected cases and 550 confirmed cases of typhoid fever were notified in Zimbabwe. A total of 276 (44.6\%) of the culture-confirmed S. Typhi isolates were analysed and 243 isolates (88.0\%) were resistant to two or more first line drugs (ciprofloxacin, ampicillin and chloramphenicol) for typhoid. The most common resistance was to ampicillin-chloramphenicol (172 isolates; 62.3\%). Increasing ciprofloxacin resistance was observed from 2012 to 2017 (4.2 to 22.0\%). Out of 161 screened isolates, 150 (93.2\%) were haplotype H58. Twelve PFGE patterns were observed among the 91 isolates analysed, suggesting some diversity exists among strains circulating in Zimbabwe. PFGE analysis of 2013, 2014 and 2016 isolates revealed a common strain with an indistinguishable PFGE pattern (100\% similarity) and indistinguishable from PFGE patterns previously identified in strains isolated from South Africa, Zambia and Tanzania.

Conclusions: Resistance to first line antimicrobials used for typhoid fever is emerging in Zimbabwe and the multidrug resistant S. Typhi H58 haplotype is widespread. A predominant PFGE clone circulating in Zimbabwe, South Africa, Zambia and Tanzania, argues for cross-border cooperation in the control of this disease.

Keywords: Antimicrobial resistance, Molecular epidemiology, Molecular sub-typing, PFGE, Salmonella Typhi, Zimbabwe

\footnotetext{
* Correspondence: mashet2006@yahoo.co.uk

${ }^{1}$ Department of Applied Biology and Biochemistry, National University of

Science and Technology, Bulawayo, Zimbabwe

${ }^{2}$ National Microbiology Reference Laboratory, Harare, Zimbabwe

Full list of author information is available at the end of the article
}

(c) The Author(s). 2019 Open Access This article is distributed under the terms of the Creative Commons Attribution 4.0 International License (http://creativecommons.org/licenses/by/4.0/), which permits unrestricted use, distribution, and reproduction in any medium, provided you give appropriate credit to the original author(s) and the source, provide a link to the Creative Commons license, and indicate if changes were made. The Creative Commons Public Domain Dedication waiver (http://creativecommons.org/publicdomain/zero/1.0/) applies to the data made available in this article, unless otherwise stated. 


\section{Background}

Typhoid fever is a significant public health problem with annual estimates of 22 million cases and 216,000 deaths worldwide [1], although the global burden is known to be underestimated, especially in developing countries where the majority of cases likely remain undiagnosed [2]. Typhoid fever is caused by Salmonella enterica serotype Typhi ( $S$. Typhi, a Gram-negative bacterium, transmitted by ingestion of faecally contaminated food or water. Culture from blood or stool remains the gold standard for typhoid diagnosis, but these methods may not be affordable or practical in low-resource settings, where serological methods have historically been used to diagnose typhoid infection. Even when culture is available, these methods can result in low recovery of the organism (40\% blood, $37 \%$ stool) and are complicated by the use of antibiotics prior to specimen collection [3]. Clinical presentation varies from a mild illness with low grade fever, malaise and dry cough to a severe clinical picture with abdominal discomfort, altered mental status and multiple complications [4]. If not treated, typhoid fever may progress to severe complications like delirium, intestinal haemorrhage, bowel perforation, and death. Humans are the only natural host and reservoir.

Typhoid fever outbreaks have been recorded in central and southern Africa, affecting both children and adults alike, including in the Democratic Republic of Congo [5], Zambia [6] and Zimbabwe [4, 7]. In Zimbabwe, more than 1000 cases of typhoid fever have been reported annually since 2011, demonstrating the endemicity of the disease. In 2009 [8], a typhoid outbreak primarily affecting two densely populated suburbs of Harare, Mabvuku and Tafara was recorded. Poor sanitation and drinking water quality in these areas and other parts of Zimbabwe were the key risk factors for $S$. Typhi transmission and outbreaks [4]. If detected early and treated with appropriate antibiotics the impact of typhoid fever on an individual and the population is greatly minimised. Antimicrobial susceptibility testing of $S$. Typhi is therefore of great importance in ensuring correct treatment regimens and for monitoring the emergence of any drug resistant strains. In Zimbabwe the treatment guidelines recommend the management of typhoid fever using ciprofloxacin and ceftriaxone [4]. An additional concern is the changing patterns of drug susceptibility for circulating strains of Typhi reported worldwide. Murgia et al. [9] reported that haplotype 58 (H58) is associated with multidrugresistance to first line drugs, and is the most diffused and rapidly expanding among $S$. Typhi population. The H58 haplotype has also been associated with extremely drug resistance (XDR) Typhoid outbreaks in Pakistan [10]. In addition to the H58 haplotype, S. Typhi with extended $\beta$-Lactamase has also been reported in Democratic Republic of Congo (DRC) [11] .However in 2016 Murgia et al. [9] reported that haplotype 58 (H58) is associated with multidrugresistance to these first line drugs, and is the most geographically dispersed and actively spreading $S$. Typhi haplotype. Surveillance of H58 S. Typhi in areas endemic for typhoid fever is therefore key in monitoring the development of resistance to first line drugs and the associated treatment choice in order to effectively minimise the associated morbidity and mortality and prevent large scale outbreaks of $S$. Typhi occurring [9].

Laboratory confirmation of enteric pathogens surveillance was established in Zimbabwe in 1995 and typhoid confirmation was limited to a few laboratories used as sentinel sites.

We present a comprehensive analysis of $S$. Typhi in Zimbabwe identified between 2009 and 2017, for antimicrobial resistance, presence of H58 haplotype and molecular epidemiology, including strain relatedness both within Zimbabwe and with strains from neighbouring countries.

\section{Methods}

\section{Clinical isolates}

Typhoid fever is one of the priority diseases in Zimbabwe and immediate notification of a suspected case is required. Samples were collected from individuals suspected of having typhoid fever are tested at regional and district medical centres. All suspected $S$. Typhi positive samples are referred to the National Microbiology Reference Laboratory (NMRL), Harare for confirmation, quality control and strain collection. For the study, all available isolates were selected.

\section{Re-culture of isolates and antimicrobial susceptibility testing}

Frozen isolates were re-cultured and serotyped based on the White-Kaufman-Le Minor standard method [12]. Confirmed $S$. Typhi isolates were screened for antibiotic susceptibility using the Kirby Bauer disc diffusion method and results were interpreted based on the 2017 CLSI guidelines [13]. The following antibiotics were used; ciprofloxacin $(5 \mu \mathrm{g})$, ceftriaxone $(30 \mu \mathrm{g})$, chloramphenicol $(30 \mu \mathrm{g})$, nalidixic acid $(30 \mu \mathrm{g})$, tetracycline $(30 \mu \mathrm{g})$ and ampicillin $(10 \mu \mathrm{g})$ (Oxoid, United Kingdom). Minimum inhibitory concentration (MIC; mg/L) for ceftriaxone, ciprofloxacin, and azithromycin were done using the E-test (bioMérieux, Marcy l'Étoile, France). Escherichia coli ATCC 25922 was used as a quality control. Multi-drug resistance (MDR) was defined as 
acquired non-susceptibility to at least one agent in three or more antimicrobial categories [14].

\section{Molecular identification of $S$. Typhi}

Deoxyribonucleic acid (DNA) was extracted using a standard heat lysis protocol. In brief a half loopful of bacterial culture (approximately $1 \mathrm{~cm}$ sweep across the agar culture) was inoculated into $400 \mu \mathrm{l}$ sterile (TrisEDTA) TE buffer and boiled for $25 \mathrm{~min}$ at $95^{\circ} \mathrm{C}$ on a heating block. The solution was allowed to cool on ice or to room temperature. Bacterial cells were spun for 3 min at $9000 \mathrm{rpm}$. A $20 \mu \mathrm{l}$ aliquot of supernatant was added to $80 \mu \mathrm{l}$ of sterile TE buffer. Quantification of crude DNA was performed using a BioDoc analyse (Biometra, Germany). Crude DNA between 5 and $10 \mathrm{ng} / \mu \mathrm{l}$ was used for polymerase chain reaction (PCR) reactions.

All the 276 isolates were confirmed using Multiplex real-time PCR targeted two genes: a gene unique to Salmonella enterica (ttrRSBCA) and a gene unique to $S$. Typhi (STY0201) $[15,16]$. The PCR reaction was carried out using a PCR master mix, TaqMan gene expression (ThermoFisher Scientific, Waltham, MA, USA), primers and probe (Table 2) in a $50 \mu \mathrm{l}$ final volume reaction. The PCR was run and results analyzed using the Applied Biosystems 7500 real time PCR system (Life Technologies, Foster City, CA) with cycling conditions as follows: $50{ }^{\circ} \mathrm{C}$ for $2 \mathrm{~min}(1 \mathrm{cycle})$, followed by $95^{\circ} \mathrm{C}$ for $10 \mathrm{~min}(1$ cycle), followed by $95^{\circ} \mathrm{C}$ for $15 \mathrm{~s}$ and $60^{\circ} \mathrm{C}$ for $1 \mathrm{~min}(40$ cycles).

\section{S. Typhi H58 haplotype screening}

Conventional PCR was used to screen 161 isolates for $S$. Typhi H58 haplotype [9] using a PCR master mix, Dream taq (ThermoFisher Scientific, Waltman, MA, USA) reagent in a $10 \mu \mathrm{l}$ reaction containing $3.68 \mu \mathrm{l}$ of nuclease free water, $5.0 \mu \mathrm{l}$ of master mix, $0.16 \mu \mathrm{l}$ of $0.4 \mu \mathrm{M}$ of each primer and $1 \mu \mathrm{l}$ of DNA template. The PCR was run using the Gene Amp PCR system 9700 (Applied Biosystems, USA). A $25 \mu \mathrm{l}$ reaction cycle was set up as follows: initial denaturation at $95^{\circ} \mathrm{C}$ for $2 \mathrm{~min}$, and 30 cycles of denaturation at $95^{\circ} \mathrm{C}$ for $30 \mathrm{~s}$, primer annealing at $58^{\circ} \mathrm{C}$ for 30 s and extension at $72^{\circ} \mathrm{C}$ for 30 s, followed by final extension at $72{ }^{\circ} \mathrm{C}$ for $7 \mathrm{~min}$. The PCR products were subjected to electrophoresis in a $1 \%$ agarose gel and visualized with ethidium bromide staining; results were checked using the Uvipro silver gel viewer (Uvitec, UK).

\section{Pulsed-field gel electrophoresis}

We used the methodology previously described by Smith et al [17] using using a PulseNet protocol [18]. A pulsotype (PT) was defined as a unique electrophoretic banding pattern. Strains with identical restriction profiles $(X b a \mathrm{I})$ were assigned as the same subtype.

\section{Results}

Between 2009 and 2017, 16,398 suspected cases and 619 confirmed cases of typhoid fever were notified in Zimbabwe (Fig. 1). A sharp increase was seen from just over 1000 cases being reported in 2011 to nearly 6000 cases in 2012 when a major outbreak was recorded. For the subsequent 5 years between 1300 and 2400 cases were reported annually. The proportion of confirmed cases ranged from 2\% in 2012 to $7 \%$ in 2017 (Table 1). No isolates were available from 2011 for analysis and it was determined that isolates from 2009 and 2010 would be utilised as the reference strains. Therefore 550 cases were confirmed during the period of interest from 2012 to 2017 and of these 276 isolates $(50 \%)$ isolated from blood and stool specimens were available in the national $S$. Typhi biobank for analysis (Table 1). PFGE results of isolates from 2009 and 2010 isolates were used as reference for molecular subtyping, as they represent the first recorded typhoid outbreak samples in Zimbabwe.

\section{Antimicrobial susceptibility assay}

A change in antimicrobial susceptibility patterns was observed for $S$. Typhi isolates annually (Fig. 2). Overall trends showed an increase in resistance to ciprofloxacin from 2012 (0\%) to 2017 (22\%) (Fig. 2). The $25.0 \%$ in 2015 was likely due to few samples available for testing. During the same timeframe high intermediate resistance $(0.5 \mathrm{mg} / \mathrm{L})$ of ciprofloxacin was also observed (Fig. 2). The ciprofloxacin-resistant isolates had MIC range of $1-2 \mathrm{mg} / \mathrm{L}$. All S. Typhi isolates were sensitive to ceftriaxone $(100 \%)$ across the sixyear period.

An increase in tetracycline resistance was observed from 2012 (11.0\%) to 2017 (46.3\%), however in 2014 and 2015 isolates were fully susceptible (Fig. 2). The isolates from 2016 and 2017 also had higher levels of resistance to tetracycline. A correlation between ciprofloxacin and tetracycline resistance was observed as depicted by pattern C and D (Table 2). Resistance of isolates to ampicillin ranged between 83.3 to $100 \%$ in all the years (Fig. 2) and resistance to chloramphenicol was similarly high at between 83 and 100\%. However, all isolates examined through 2017, remained susceptible to ceftriaxone and azithromycin.

A total of 11 resistance patterns were observed (Table 2). Pattern A resistance to ampicillin and chloramphenicol was the most common pattern (62.3\%) among $S$. Typhi isolates (Table 2). Other prevalent resistotypes included Pattern C (ciprofloxacin-tetracycline-ampicillinchloramphenicol) and Pattern I (tetracycline-ampicillinchloraphenicol). A total of $243 S$. Typhi isolates (88. 0\%) were multi drug resistant as they were resistant to two or more drugs (Table 2). 


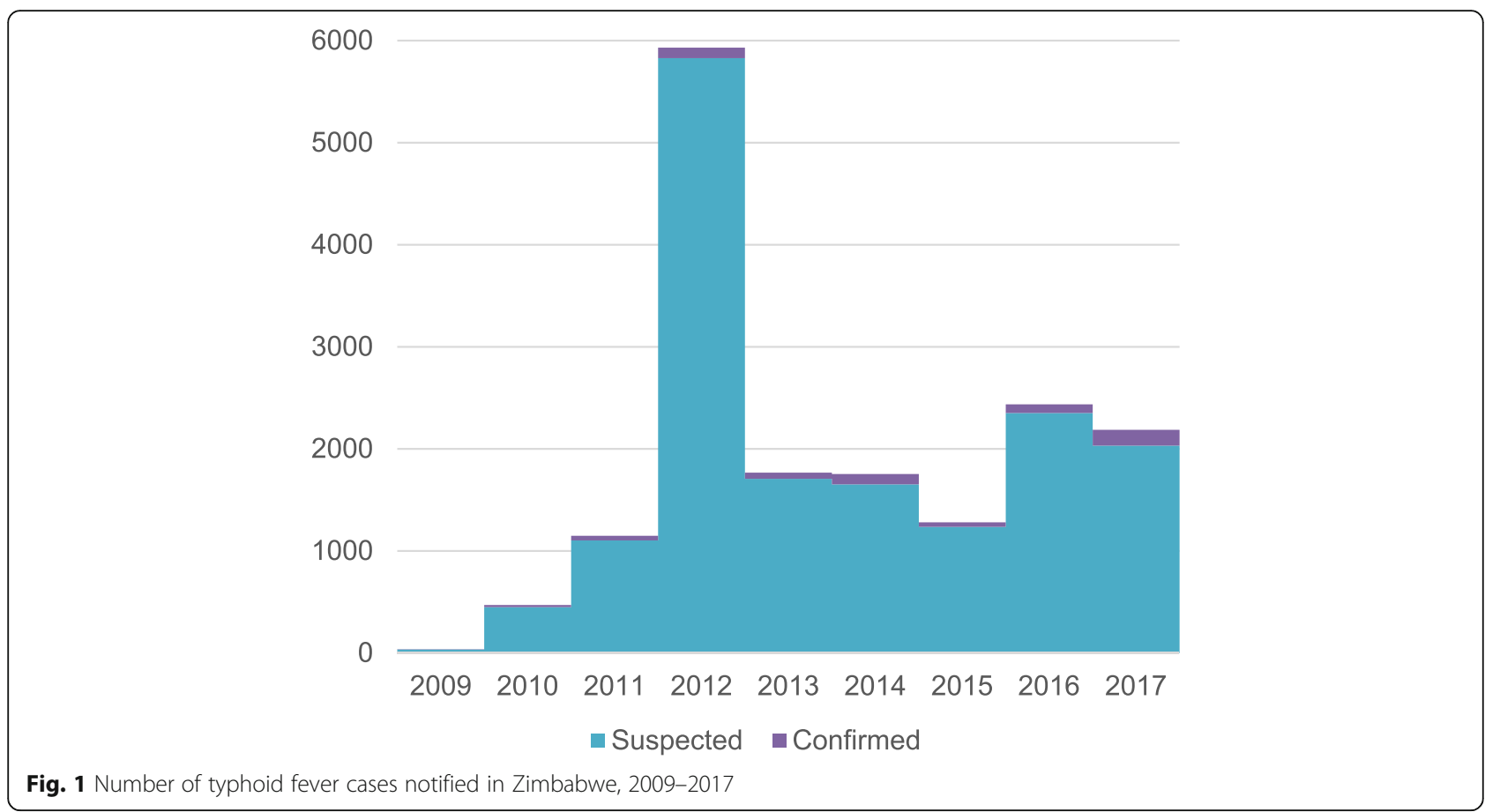

\section{Haplotype screening}

Of the 161 isolates selected based on resistance patterns were screened for H58 haplotype, 150 were positive (93.2\%) (data not shown). All the H58 positive isolates were resistant to ampicillin, chloramphenicol and others showed reduced susceptibility to ciprofloxacin. The results of the study shows that H58 associated MDR are widespread among $S$. Typhi isolates in Zimbabwe.

\section{Molecular subtyping of $S$. Typhi}

A total of 91 (33\%) isolates were selected from the 276 isolates using analytical cross sectional study design to cater for heterogeneous characteristics like year of isolation, antimicrobial susceptibility testing results and geographical area of isolation. The geographic origins of the 91 isolates included Harare, Chegutu, Mutare, Inyanga, Mutawatawa, Rusape, Chitungwiza and Bindura. Dendrogram analysis of PFGE patterns for isolates showed that percentage pattern similarity values ranged between 46 and $100 \%$. The discrimination index was high for PFGE and the technique was able to distinguish between isolates. There was high genetic diversity among $S$. Typhi isolates as the 91 isolates were differentiated into a total of 12 PFGE subtypes. The $2009 \mathrm{~S}$. Typhi PFGE subtype was indistinguishable $(100 \%$ similar) from the subtypes of the 2011 isolates and to $68.3 \%$ of the 2012 isolates (Additional file 1: Figure S1). The $2013(8 / 9), 2014(6 / 14)$ and $2016(14 / 20)$ isolates had subtypes that were $97 \%$ similar to the 2009 subtype. A common $S$. Typhi subtype was noted to be circulating in Harare, Mutawatawa, Chitungwiza, Mutare, Rusape and Inyanga. PFGE analysis of the 2012, 2013, 2014 and 2016 subtype revealed an indistinguishable PFGE pattern with the isolates from South Africa (2017), Zambia (2015) and Tanzania (2012) (Fig. 3). It also revealed that the 2009 Mabvuku subtype was 100\% similar to the 2006 and 2008 Gauteng, South Africa isolates (Additional file 1: Figure S1). Molecular subtyping of the ciprofloxacin-resistant isolates from different suburbs in Harare, revealed that they all shared a similar subtype.

Table 1 Proportion of confirmed cases and retrieved S. Typhi isolates analysed, Zimbabwe, 2012-2017

\begin{tabular}{|c|c|c|c|c|c|c|}
\hline Year & $\begin{array}{l}\text { No. suspected } \\
\text { cases }\end{array}$ & $\begin{array}{l}\text { No. of confirmed } \\
\text { cases }\end{array}$ & $\begin{array}{l}\text { Proportion of all } \\
\text { cases confirmed }\end{array}$ & $\begin{array}{l}\text { No. isolates retrieved } \\
\text { for analysis }\end{array}$ & $\begin{array}{l}\text { Proportion of all cases with } \\
\text { isolates available }\end{array}$ & $\begin{array}{l}\text { Proportion of confirmed } \\
\text { cases with isolates available }\end{array}$ \\
\hline 2012 & 5829 & 103 & $2 \%$ & 101 & $2 \%$ & $98 \%$ \\
\hline 2013 & 1707 & 61 & $3 \%$ & 36 & $2 \%$ & $59 \%$ \\
\hline 2014 & 1653 & 101 & $6 \%$ & 24 & $1 \%$ & $24 \%$ \\
\hline 2015 & 1236 & 45 & $4 \%$ & 4 & $0 \%$ & $9 \%$ \\
\hline 2016 & 2352 & 85 & $3 \%$ & 70 & $3 \%$ & $82 \%$ \\
\hline 2017 & 2032 & 155 & $7 \%$ & 41 & $2 \%$ & $26 \%$ \\
\hline
\end{tabular}




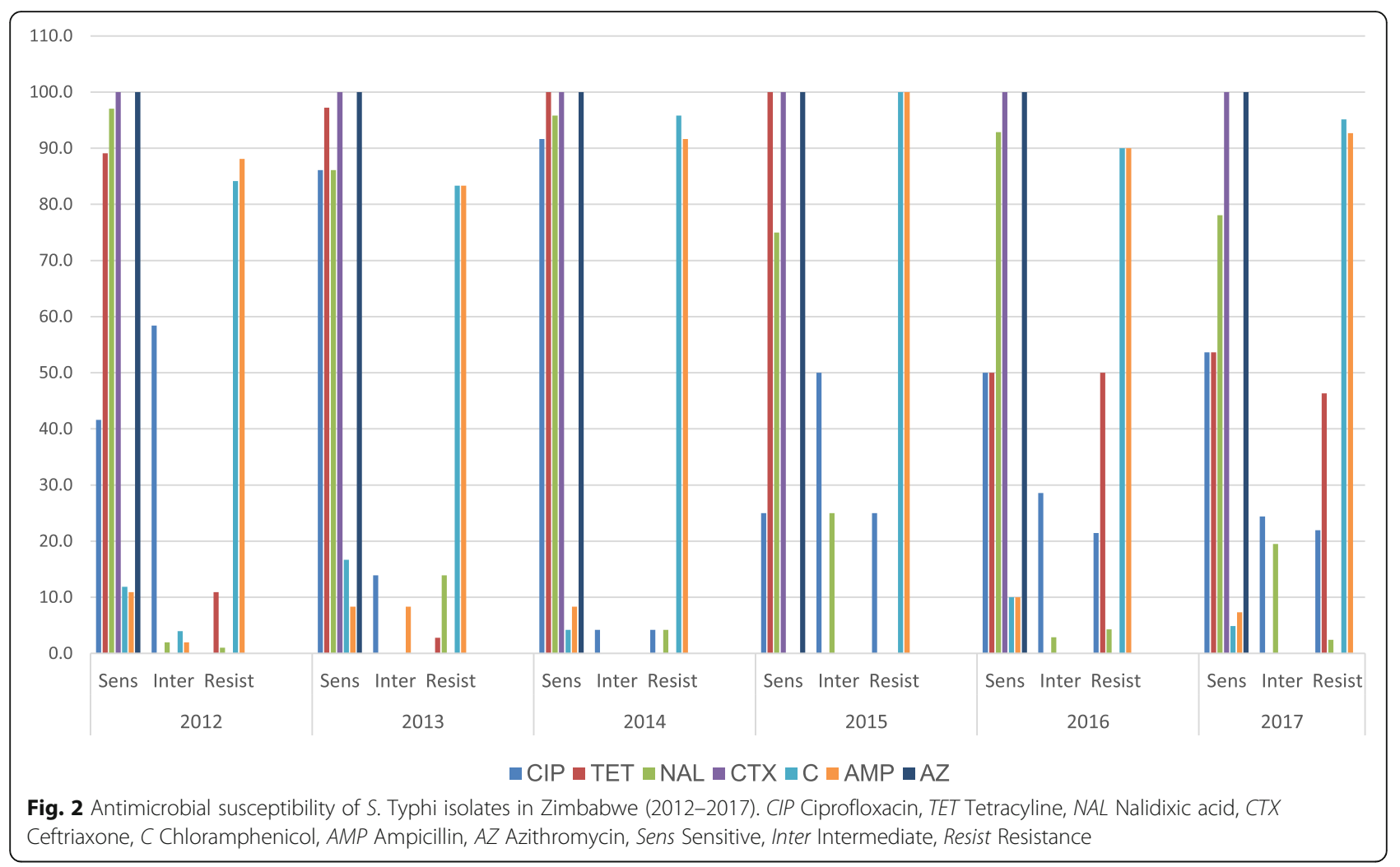

\section{Discussion}

To provide guidance on appropriate treatment choice in order to minimise the morbidity and mortality associated with typhoid fever and prevent large scale outbreaks a phenotypic and genotypic analysis was conducted on S. Typhi isolates collected from 2012 to 2017. To determine the development of drug resistance to first line antibiotics for typhoid fever and the prevalence of Salmonella enterica serotype Typhi ( $S$.

Table 2 Resistotypes of 276 S. Typhi isolates in Zimbabwe (2012-2017)

\begin{tabular}{llll}
\hline Pattern & Number of isolates & Percentage & Resistotypes \\
\hline A & 172 & 62.3 & AMP-C \\
B & 1 & 0.4 & CIP-AMP-C \\
C & 20 & 7.2 & CIP-TET-AMP-C \\
D & 1 & 0.4 & CIP-TET-AMP \\
E & 1 & 0.4 & CIP-NAL-AMP-C \\
F & 2 & 0.7 & NAL-AMP \\
G & 6 & 2.2 & NAL-AMP-C \\
H & 3 & 1.1 & TET-C \\
I & 32 & 11.6 & TET-AMP-C \\
K & 3 & 1.1 & TET-AMP \\
L & 2 & 0.7 & TET-NAL-AMP \\
\hline
\end{tabular}

CIP Ciprofloxacin, TET Tetracyline, NAL Nalidixic acid, CTX Ceftriaxone, C Chloramphenicol, AMP Ampicillin, AZ Azithromycin
Typhi) H58 haplotype standardised methodology were performed. S. Typhi isolates showed a changing pattern in antimicrobial susceptibility across the years for which isolates were available (2012-2017). Fluoroquinolones such as ciprofloxacin are recommended by WHO [19], as they are reliably effective, inexpensive and well-tolerated drugs for the treatment of typhoid fever [19]. Ciprofloxacin is used as a first line treatment drug for typhoid in Zimbabwe [4]. In this study, an increase in resistance to ciprofloxacin was observed from the $2014(4.2 \%)$ to 2017 (22.0\%) isolates (Fig. 2). The ciprofloxacin-resistant isolates were from Harare with Budiriro and Glenview having the highest number in 2016. These ciprofloxacin-resistant isolates have spread to others areas like Mbare, Kambuzuma, Kuwadzana and Hatcliff. Also an increase in intermediate resistance $(0.5 \mathrm{mg} / \mathrm{L})$ of ciprofloxacin was recorded from 2014 to 2017 (Fig. 2). Intermediate resistance was observed in 5 isolates from Mutare in 2016. An MIC value $0.5 \mathrm{mg} / \mathrm{L}$ was recorded in all isolates showing intermediate resistance meaning ciprofloxacin may be effective at higher doses. Though fluoroquinolone resistance is chromosomally mediated [6], selective pressures exerted by the overuse of these drugs may result in such isolates becoming more common in the future. This may explain the increase in ciprofloxacin resistance in $S$. Typhi isolates in Zimbabwe (especially in Harare) where the antibiotic 


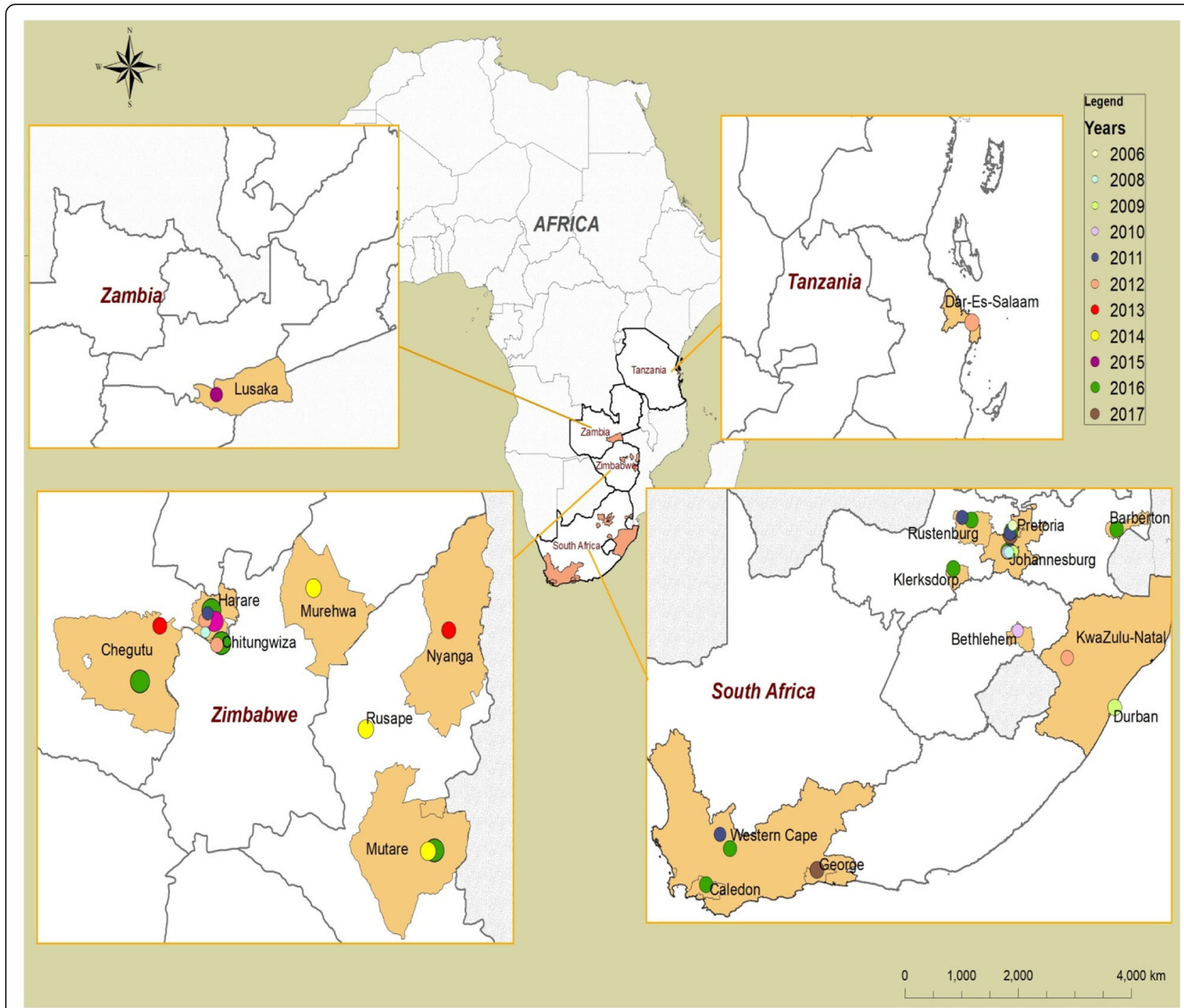

Fig. 3 Distribution of S. Typhi PFGE clone in South Africa, Tanzania, Zambia and Zimbabwe, 2006-2017

is used as a broad-spectrum drug to treat many diseases. Resistance and intermediate resistance to ciprofloxacin has been reported from many regions worldwide, including Kenya [20], Cambodia [21], Bangladesh [22] and South Africa [23]. A sharp increase in tetracycline resistance was observed from $2012(11.0 \%)$ to 2017 (46.3\%) (Fig. 2). All the tetracycline-resistant $S$. Typhi isolates from 2016 were isolated in Harare. In Zimbabwe, tetracycline is not used as a drug of choice for the treatment of typhoid fever but it is heavily used in the poultry industry and may be indicative of human exposure to residual antibiotics in the food chain. Strains that acquire this type of resistance also become co-resistant to other antibiotics such as Beta-lactams and fluoroquinolones, if resistance is plasmid-borne [24]. A correlation between tetracycline and ciprofloxacin resistance was observed (Table 2). In this study, all the ciprofloxacin resistant strains were susceptible to ceftriaxone and azithromycin (Fig. 2).

All the isolates from 2012 to 2017 were susceptible to ceftriaxone (Fig. 2). Intravenous ceftriaxone is a drug of choice for typhoid treatment in Zimbabwe [4]. In addition, it is used to treat typhoid fever due to resistant bacteria [19]. Resistance to older first-line drugs for $S$. Typhi such as ampicillin and chloramphenicol remained constantly high ranging from 83.3 to $100 \%$ (Fig. 2). In a similar study done in India, $75.5 \%$ of $S$. Typhi isolates were resistant to amoxicillin [25]. Ampicillin resistance can be used to predict resistance of $S$. Typhi to amoxicillin [13]. Globally, extremely high resistance to ampicillin and chloramphenicol, $[5,25,26]$ has motivated for the 
use of alternate antibiotics for typhoid fever, but our results suggest that increasing ciprofloxacin resistance may soon render this antimicrobial ineffective in typhoid fever control programmes. Our findings warrant an adjustment in typhoid treatment guidelines and a shift towards evidence based management and routine antimicrobial resistance surveillance programs in Zimbabwe.

Multidrug resistant strains are a major therapeutic concern for physicians in developing countries. Contributing factors may include antimicrobial misuse and inappropriate prescribing practices [27] as well as intrinsic plasmid-mediated factors [22, 28, 29]. Eleven multidrug resistance patterns were observed and the most common pattern, resistotype A (resistance to ampicillinchloramphenicol) was exhibited by $172(62.3 \%)$ isolates (Table 2). The high level of resistance to first-line antimicrobials for treatment of typhoid fever is worrisome, as $243 \mathrm{~S}$. Typhi isolates (88.0\%) were resistant to two or more antimicrobials and 150 of the 161 tested belonged to the H58 haplotype. Results of the study suggest high prevalence of MDR H58 haplotype in clinical S. Typhi isolates in Zimbabwe. According to a study done by Wong et al. [29] 63\% of $S$. Typhi isolates belonged to H58 lineage in Eastern and Southern Africa. The H58 lineages I and II were detected in Kenya, Tanzania, Malawi and South Africa [30], neighbouring countries to Zimbabwe.

Outbreaks of MDR S. Typhi strains have been reported around the world. In 2011, researchers in Malawi isolated MDR H58- lineage $S$. Typhi in Blantyre, Malawi [31]. Multidrug resistant strains of S. Typhi have been reported from many African countries, including Kenya, Uganda, Tanzania and Ghana [32]. Due to the presence of MDR and quinolone-resistantS. Typhi isolates [33], it has been recommended that developing countries should use azithromycin as a first-priority drug.

PFGE analysis was used for molecular subtyping of isolates and to determine relatedness of $91 \mathrm{~S}$. Typhi isolates from 2009 to 2016. PFGE is a powerful molecular biology technique which has provided important insights into the epidemiology and population biology of many pathogens in the world [34]. In the present study, 12 PFGE subtypes were shown amongst the 91 isolates. PFGE is regarded as one of the most reliable techniques for discriminating different strains of $S$. Typhi $[35,36]$. The same subtype observed for the 2009 Mabvuku isolates was consistently seen in South African samples of 2006, 2008, 2009, 2010, 2011, 2012, 2016 and 2012 (Zimbabwe) (Additional file 1: Figure S1, Fig. 3) suggesting that the strain is circulating in Zimbabwe and South Africa. The Mabvuku 2009 subtype was noted to be circulating in Harare (2013; 2016), Mutawatawa (2014), Chitungwiza (2012), Mutare (2016), Rusape (2014) and Inyanga (2013), demonstrating a relationship between isolates across a wide area and timeline. These findings point toward Mabvuku as the source of 2009 typhoid resurgence in Harare, Zimbabwe. Some PFGE subtypes were unique to particular towns such as Masvingo, $\mathrm{Mu}$ tare and Chegutu.

Resistance traits (e.g. fluoroquinolone resistance) were highly subtype-specific, suggesting predominantly subclonal distribution. Although the proportion of all cases with an available isolate is small due to the sampling process within a country these findings still remain key in advancing our understanding of the genetic structure, ecology, geographic distribution, and emergence of this widely disseminated drug-resistant pathogen, which represents a growing public health threat. It does however point to the need to improve sample collection processes for individuals suspected of having typhoid fever. Our research findings also revealed that there is a common $S$. Typhi strain circulating in Zimbabwe, South Africa, Zambia and Tanzania as evidenced by a common subtype in the isolates (Fig. 3). Imanishi et al. [8] also observed that there was a common subtype circulating in Zimbabwe, Malawi and Tanzania when they analyzed their 2009 and 2011 isolates. Similarities between PFGE subtypes from multiple countries may be the result of population movements in Zimbabwe, Zambia, South Africa and Tanzania where people move easily from one country to another.

\section{Conclusions}

In Zimbabwe there is emerging antimicrobial resistance to first line drugs (ciprofloxacin, amoxicillin and chloramphenicol) used for typhoid treatment and widespread distribution of MDR H58 S. Typhi isolates. Treatment recommendations should therefore be based on these laboratory sensitivity results. $S$. Typhi strains in Zimbabwe are presently susceptible to ceftriaxone and azithromycin: use of these drugs for treatment of typhoid fever should be promoted. PFGE results suggest there are 12 strains of $S$. Typhi in circulation in Zimbabwe and that the 2009 Mabvuku strain is still in circulation. A better understanding of the molecular epidemiology of $S$. Typhi in Zimbabwe can greatly contribute to the prevention and control of outbreaks as well as determine cross-border spread by providing the scientific evidence to develop appropriate comprehensive and integrated strategies.

\section{Additional file}

Additional file 1: Figure S1. PFGE analysis of the Zimbabwe (2009) with South Africa (2006, 2008, 2009, 2010, 2011 and 2012) S. Typhi isolates. (DOCX $187 \mathrm{~kb})$

\section{Abbreviations}

CLSI: Clinical and Laboratory Standards Institute; DNA: Deoxyribonucleic acid; DRC: Democratic Republic of Congo; MDR: Multi-drug resistance;

NMRL: National Microbiology Reference Laboratory; PFGE: Pulsed-field gel 
electrophoresis; TE: Tris- EDTA; USA: United States of America; WHO: World Health Organization; XDR: Extremely drug resistance

\section{Acknowledgements}

We acknowledge all the laboratories that participated in this study. We thank Mrs. Govore (Beatrice Road Infectious Road Hospital), Mr. Chawira (Beatrice Road Infectious Road Hospital), Esther Hamblion (World Health Organisation, Regional Office for Africa) and Rachael Aubert (Center for Diseases and Control, Atlanta USA) for assistance with data processing.

\section{Authors' contributions}

TM developed the concept of the study, performed antimicrobial susceptibility testing and molecular analysis and drafted the manuscript. MGM, AT, EM and SMZ supervised, revised article for publication and contributed with data analysis. SLS, AS and AMS designed, supervised and revised the manuscript. All authors have seen and approved the manuscript and have significantly contributed to the work. BSP and JM developed the concept of the study, supervised and revised the manuscript.

\section{Funding}

This study was funded by the Letten Foundation Research Centre, Harare, Zimbabwe, the Global Disease Detection grant 1U19GH000571-02 of the Centers for Disease Control and Prevention, Atlanta, USA through the National Institute of Communicable Diseases, Johannesburg, South Africa, and the National Microbiology Reference Laboratory, Zimbabwe. These funding organisations only provided financial support and did not influence the research design, implementation or dissemination of its findings.

\section{Availability of data and materials}

The datasets analyzed during the current study are available from the corresponding author on reasonable request.

\section{Ethics approval and consent to participate}

Ethical approval was sought and granted by the Medical Research Council of Zimbabwe (MRCZ/B/1066). Stored bacterial isolates not linked to patient information were used and informed consent was waived by Medical Research Council of Zimbabwe.

\section{Consent for publication}

Not applicable.

\section{Competing interests}

The authors declare that they have no competing interests.

\section{Author details}

'Department of Applied Biology and Biochemistry, National University of Science and Technology, Bulawayo, Zimbabwe. ${ }^{2}$ National Microbiology Reference Laboratory, Harare, Zimbabwe. ${ }^{3}$ Letten Foundation Research Centre, Harare, Zimbabwe. ${ }^{4}$ Division of Women, Rikshospitalet, Oslo University Hospital and Institute of Clinical Medicine, University of Oslo, Oslo, Norway. ${ }^{5}$ Centre for Enteric Diseases, National Institute for Communicable Diseases, National Health Laboratory Service, Johannesburg, South Africa. ${ }^{6}$ Faculty of Health Sciences, University of the Witwatersrand, Johannesburg, South Africa.

\section{Received: 15 February 2018 Accepted: 20 May 2019}

\section{Published online: 31 May 2019}

\section{References}

1. Crump JA, Luby SP, Mintz ED. The global burden of typhoid fever. Bull World Health Organ. 2004;82:346-53.

2. Tarupiwa A, Tapera S, Mtapuri-Zinyowera S, Gumbo P, Ruhanya V, Gudza-Mugabe M, Majuru NX, Chin'ombe N. Evaluation of TUBEX-TF and OnSite typhoid $\mathrm{lgG} / \mathrm{lgM}$ combo rapid tests to detect Salmonella enterica serovar Typhi infection during a typhoid outbreak in Harare, Zimbabwe. BMC Res Notes. 2015;8(1):50.

3. Gilman R, Terminel M, Levine M, Hernandez-Mendoza P, Hornick R. Relative efficacy of blood, urine, rectal swab, bone-marrow, and rosespot cultures for recovery of Salmonella typhi in typhoid fever. Lancet. 1975;305(7918):1211-3.
4. Organization WH: Guidelines for the management of typhoid fever. H Aid Zimbabwe, European Commission 2011.

5. Lunguya O, Lejon V, Phoba M-F, Bertrand S, Vanhoof R, Verhaegen J, Smith AM, Keddy KH, Muyembe-Tamfum J-J, Jacobs J. Salmonella typhi in the Democratic Republic of the Congo: fluoroquinolone decreased susceptibility on the rise. PLoS Negl Trop Dis. 2012;6(11):e1921.

6. Mwansa J, Lukwesa C, Hendriksen R, Kalonda A, Kwenda G. Genomic signature of multi-drug resistant Salmonella typhi related to the massive outbreak in Zambia year 2010 to 2012. Int J Infect Dis. 2014;21:260.

7. Muti M, Gombe N, Tshimanga M, Takundwa L, Bangure D, Mungofa S, Chonzi P. Typhoid outbreak investigation in Dzivaresekwa, suburb of Harare City, Zimbabwe. 2011 Pan Afr Med J. 2014;18(1):309.

8. Imanishi M, Kweza PF, Slayton RB, Urayai T, Ziro O, Mushayi W, FrancisChizororo M, Kuonza LR, Ayers T, Freeman MM. Household water treatment uptake during a public health response to a large typhoid fever outbreak in Harare, Zimbabwe. Am J Trop Med Hyg. 2014;90(5): 945-54.

9. Murgia M, Rubino S, Wain J, Gaind R, Paglietti B. A novel broadly applicable PCR-RFLP method for rapid identification and subtyping of H58 Salmonella Typhi. J Microbiol Methods. 2016;127:219-23.

10. Klemm EJ, Shakoor S, Page AJ, Qamar FN, Judge K, Saeed DK, Wong VK, Dallman TJ, Nair S, Baker S. Emergence of an extensively drug-resistant Salmonella enterica serovar Typhi clone harboring a promiscuous plasmid encoding resistance to fluoroquinolones and third-generation cephalosporins. MBio. 2018;9(1):e00105-00118.

11. Phoba M-F, Barbé $B$, Lunguya $O$, Masendu L, Lulengwa D, Dougan $G$, Wong VK, Bertrand S, Ceyssens P-J, Jacobs J. Salmonella enterica serovar Typhi producing CTX-M-15 extended spectrum $\beta$-lactamase in the Democratic Republic of the Congo. Clin Infect Dis. 2017;65(7):1229-31.

12. Grimont PA, Weill F-X. Antigenic formulae of the Salmonella serovars. WHO collaborating centre for reference and research on Salmonella, vol. 9; 2007. p. 1-166.

13. Wayne P. Clinical and laboratory standards institute (CLSI). In: Performance standards for antimicrobial susceptibility testing 2017; 2017. p. 27.

14. Magiorakos AP, Srinivasan A, Carey R, Carmeli Y, Falagas M, Giske C, Harbarth S, Hindler J, Kahlmeter G, Olsson-Liljequist B. Multidrug-resistant, extensively drug-resistant and pandrug-resistant bacteria: an international expert proposal for interim standard definitions for acquired resistance. Clin Microbiol Infect. 2012;18(3):268-81.

15. Malorny B, Paccassoni E, Fach P, Bunge C, Martin A, Helmuth R. Diagnostic real-time PCR for detection of Salmonella in food. Appl Environ Microbiol. 2004:70(12):7046-52.

16. Nga TVT, Karkey A, Dongol S, Thuy HN, Dunstan S, Holt K, Campbell Jl, Chau $\Pi$, Chau NW, Arjyal A. The sensitivity of real-time PCR amplification targeting invasive Salmonella serovars in biological specimens. BMC Infect Dis. 2010;10(1):125.

17. Smith AM, Njanpop-Lafourcade B-M, Mengel MA, Gessner BD, Sauvageot D, Bidjada B, Miwanda BN, Saliou DM, N'Douba AK, Langa JP. Comparative characterization of Vibrio cholerae 01 from five sub-Saharan African countries using various phenotypic and genotypic techniques. PLoS One. 2015:10(11):e0142989.

18. Control CD. Prevention: standard operating procedure for PulseNet PFGE of Escherichia coli O157: H7, Escherichia coli non-O157 (STEC), Salmonella serotypes, Shigella sonnei and Shigella flexneri. Atlanta: Centers for Disease Control and Prevention; 2013.

19. World Health Organization. Background document: the diagnosis, treatment and prevention of typhoid fever. In: Background document: The diagnosis, treatment and prevention of typhoid fever; 2003.

20. Mengo DM, Kariuki S, Muigai AW, Revathi GN. Trends in Salmonella enteric serovar Typhi in Nairobi, Kenya from 2004 to; 2010

21. Vlieghe ER, Phe T, De Smet B, Veng CH, Kham C, Bertrand S, Vanhoof R, Lynen L, Peetermans WE, Jacobs JA. Azithromycin and ciprofloxacin resistance in Salmonella bloodstream infections in Cambodian adults. PLoS Negl Trop Dis. 2012;6(12):e1933.

22. Mannan A, Shohel M, Rajia S, Mahmud NU, Kabir S, Hasan I. A cross sectional study on antibiotic resistance pattern of Salmonella typhi clinical isolates from Bangladesh. Asian Pac J Trop Biomed. 2014:4(4):306-11.

23. Feasey NA, Archer BN, Heyderman RS, Sooka A, Dennis B, Gordon MA, Keddy KH. Typhoid fever and invasive nontyphoid salmonellosis, Malawi and South Africa. Emerg Infect Dis. 2010;16(9):1448. 
24. Cohen SP, McMurry L, Hooper D, Wolfson J, Levy S. Cross-resistance to fluoroquinolones in multiple-antibiotic-resistant (mar) Escherichia coli selected by tetracycline or chloramphenicol: decreased drug accumulation associated with membrane changes in addition to OmpF reduction. Antimicrob Agents Chemother. 1989;33(8):1318-25.

25. Sharma P, Dahiya S, Manral N, Kumari B, Kumar S, Pandey S, Sood S, Das BK Kapil A. Changing trends of culture-positive typhoid fever and antimicrobial susceptibility in a tertiary care north Indian hospital over the last decade. Indian J Med Microbiol. 2018;36(1):70.

26. Onyango D, Machioni F, Kakai R, Waindi E. Multidrug resistance of Salmonella enterica serovars Typhi and typhimurium isolated from clinical samples at two rural hospitals in Western Kenya. J Infect Dev Ctries. 2008;2(02):106-11.

27. Kotwani A, Wattal C, Joshi P, Holloway K. Irrational use of antibiotics and role of the pharmacist: an insight from a qualitative study in New Delhi, India. J Clin Pharm Ther. 2012;37(3):308-12.

28. Kumar Y, Sharma A, Mani KR. Antibiogram profile of Salmonella enterica serovar typhi in India-a two year study. Trop Life Sci Res. 2013;24(1):45.

29. Alhomoud F, Almahasnah R, Alhomoud FK. "You could lose when you misuse"-factors affecting over-the-counter sale of antibiotics in community pharmacies in Saudi Arabia: a qualitative study. BMC Health Serv Res. 2018; 18(1):915.

30. Wong VK, Baker S, Pickard DJ, Parkhill J, Page AJ, Feasey NA, Kingsley RA, Thomson NR, Keane JA, Weill F-X. Phylogeographical analysis of the dominant multidrug-resistant H58 clade of Salmonella Typhi identifies interand intracontinental transmission events. Nat Genet. 2015;47(6):632.

31. Feasey NA, Gaskell K, Wong V, Msefula C, Selemani G, Kumwenda S, Allain TJ, Mallewa J, Kennedy N, Bennett A. Rapid emergence of multidrug resistant, H58-lineage Salmonella typhi in Blantyre, Malawi. PLoS Negl Trop Dis. 2015;9(4):e0003748.

32. Park SE, Pham DT, Boinett C, Wong VK, Pak GD, Panzner U, Espinoza LMC, von Kalckreuth V, Im J, Schütt-Gerowitt $H$. The phylogeography and incidence of multi-drug resistant typhoid fever in sub-Saharan Africa. Nat Commun. 2018;9(1):5094.

33. Butler T. Treatment of typhoid fever in the 21 st century: promises and shortcomings. Clin Microbiol Infect. 2011;17(7):959-63.

34. Singh SP, Salamon H, Lahti CJ, Farid-Moyer M, Small PM. Use of pulsed-field gel electrophoresis for molecular epidemiologic and population genetic studies ofMycobacterium tuberculosis. J Clin Microbiol. 1999;37(6):1927-31.

35. Fendri I, Hassena AB, Grosset N, Barkallah M, Khannous L, Chuat V, Gautier M, Gdoura R. Genetic diversity of food-isolated Salmonella strains through pulsed field gel electrophoresis (PFGE) and enterobacterial repetitive intergenic consensus (ERIC-PCR). PLoS One. 2013;8(12):e81315.

36. Shariat N, Sandt CH, DiMarzio MJ, Barrangou R, Dudley EG. CRISPR-MVLST subtyping of Salmonella enterica subsp. enterica serovars typhimurium and Heidelberg and application in identifying outbreak isolates. BMC Microbiol. 2013;13(1):254

\section{Publisher's Note}

Springer Nature remains neutral with regard to jurisdictional claims in published maps and institutional affiliations.

\section{Ready to submit your research? Choose BMC and benefit from:}

- fast, convenient online submission

- thorough peer review by experienced researchers in your field

- rapid publication on acceptance

- support for research data, including large and complex data types

- gold Open Access which fosters wider collaboration and increased citations

- maximum visibility for your research: over $100 \mathrm{M}$ website views per year

At $\mathrm{BMC}$, research is always in progress.

Learn more biomedcentral.com/submissions 